\title{
PENGARUH STRESSOR SUHU DAN SALINITAS TERHADAP PERKEMBANGAN EMBRIO IKAN NILEM (Osteochilus hasselti)
}

\author{
Vitas Atmadi Prakoso ${ }^{1)^{*}}$ dan Kurniawan ${ }^{2)}$ \\ ${ }^{1)}$ Balai Penelitian dan Pengembangan Budidaya Air Tawar \\ 2) Aquaculture graduate Student, Flinders University-Australia \\ email: vitas.atmadi@gmail.com
}

\section{ABSTRACT \\ Effects of Temperature and Salinity as Stressors on Embryo Development of Hard- Lipped Barb (Osteochilus Hasselti)}

\begin{abstract}
Exposure to environmental stressors on fish is an aspect of concern to researchers because its effects can be detrimental to metabolism, growth, disease resistance, reproductive ability, health, and survival of the fish. Although, according to the researchers that stress can be bad for the fish, but this stress phenomenon remains to be studied more deeply. Based on this information, this paper is made to assess the effects of environmental stressors on fish, especially in hard-lipped barb (Osteochilus hasselti) on the embryonic developmental stages. The data collected comes from the results of research conducted at Institute for Freshwater Aquaculture Research and Development (IFARD), Bogor. This paper discussed about temperature and salinity as environmental stressors related to development of early life stage of hard-lipped barb. Hatching, mortality, and survival rates were the indicators of environmental stressors decisive influence on the development of the embryo. In addition, the observation of embryonic development through the microscope is also used as supporting data. Based on research data, it was concluded that environmental stressors such as temperature and salinity beyond the limits of tolerance could interfere with embryonic development of fish nilem. The stressor temperatures for the embryonic development of hard-lipped barb were $25^{\circ} \mathrm{C}$ and $31^{\circ} \mathrm{C}$, while the salinity stressor for hard-lipped barb embryos was above 5 ppt. The results of this study could be used as reference in fish farming activities of hard-lipped barb to optimize seedling production.
\end{abstract}

Key Words: Osteochilus hasselti, embryo development, environmental stressors, temperature, salinity

\begin{abstract}
ABSTRAK
Paparan terhadap stressor lingkungan pada ikan merupakan aspek yang menjadi perhatian bagi peneliti karena efeknya dapat merugikan metabolisme, pertumbuhan, ketahanan terhadap penyakit, kemampuan reproduksi, kesehatan, dan kelangsungan hidup ikan. Meskipun menurut para peneliti bahwa stress dapat berakibat buruk bagi ikan, namun fenomena stress ini masih perlu dipelajari lebih dalam lagi. Berdasarkan informasi tersebut, tulisan ini dibuat untuk mengkaji pengaruh stressor lingkungan terhadap ikan, khususnya pada spesies ikan nilem (Osteochilus hasselti) pada fase perkembangan embrio. Data yang dikumpulkan berasal dari hasil penelitian yang dilaksanakan di BPPBAT, Bogor. Jenis stressor lingkungan yang akan dibahas pada tulisan ini yaitu suhu dan salinitas. Derajat penetasan, mortalitas, dan tingkat kelangsungan hidup merupakan indikator penentu pengaruh stressor lingkungan terhadap perkembangan embrio. Selain itu, pengamatan perkembangan embrio melalui mikroskop juga dijadikan sebagai data pendukung. Berdasarkan data penelitian, dapat disimpulkan bahwa stressor lingkungan berupa suhu dan salinitas di luar batas toleransi dapat mengganggu perkembangan embrio ikan nilem. Suhu yang bersifat stressor bagi perkembangan embrio ikan nilem yaitu $25^{\circ} \mathrm{C}$ dan $31^{\circ} \mathrm{C}$, sedangkan stressor salinitas bagi embrio ikan nilem yaitu di atas 5 ppt. Hasil dari studi ini dapat dijadikan sebagai acuan dalam kegiatan budidaya ikan nilem untuk mengoptimalkan produksi benih.
\end{abstract}

Kata Kunci: Osteochilus hasselti, Perkembangan embrio, stressor lingkungan, suhu, salinitas 


\section{PENDAHULUAN}

Penyebab stress (stressor) fisik, kimia, dan yang lainnya pada ikan dapat memicu efek fisiologis dan efek lainnya. Selain itu, paparan berulang terhadap stressor ringan juga dapat mengubah kebiasaan ikan serta melemahkan neuroendokrin dan respon metabolik terhadap paparan stressor berikutnya (Iwama et al., 1998; Reid et al., 1998). Intensitas stressor yang terlalu parah akan berpengaruh negatif terhadap kesehatan dan kondisi ikan, sehingga menjadi maladaptif. Kondisi ini dikenal juga sebagai "distress" (Selye, 1974; Barton \& Iwama, 1991).

Tahap perkembangan embrio pada ikan merupakan tahap yang paling sensitif dalam seluruh siklus hidup ikan. Dalam reproduksi ikan budidaya, perkembangan embrio dan larva merupakan hal yang harus diperhatikan, karena berkaitan dengan kualitas maupun kuantitas benih yang dihasilkan. Jumlah telur yang menetas dan tingkat kelangsungan hidup larva ikan dalam kegiatan produksi benih dipengaruhi oleh beberapa jenis stressor lingkungan dapat mengakibatkan rendahnya tingkat produksi benih ikan. Dua faktor diantaranya yaitu suhu (Heming \& Buddington, 1988; Hallare et al., 2005) dan salinitas (Petereit et al., 2008; Haque et al., 2014). Suhu dan salinitas di luar batas toleransi dapat mengakibatkan kegagalan penetasan telur.

Beberapa penelitian telah banyak dilakukan mengenai pengaruh stressor lingkungan terhadap perkembangan telur dan kelangsungan hidup larva pada beberapa jenis ikan, khususnya pada jenis stressor suhu (Réalis-Doyelle et al., 2016; Ayala et al., 2016; Berlinsky et al., 2004) dan salinitas (DiMaggio et al., 2016; Bonisławska et al., 2014; Bonisławska, 2009; Navarro et al., 2014; Diana et al., 2011; Dhaneesh et al., 2012). Namun, informasi mengenai pengaruh stressor lingkungan terhadap perkembangan embrio dan kelangsungan hidup larva ikan nilem (Osteochilus hasselti) masih belum banyak dipelajari. Padahal informasi tersebut sangat penting untuk mendukung optimalisasi pembenihan ikan nilem. Ikan ini merupakan jenis ikan daerah tropis yang umumnya hidup pada kisaran suhu optimal $18-28^{\circ} \mathrm{C}$ (Soeseno, 1985; Riehl \& Baensch, 1991) dan toleransi salinitas $\leq 6$ ppt (Amrullah et al., 2015), serta merupakan salah satu spesies ikan yang ekonomis untuk dibudidayakan (Subagja et al., 2006). Tulisan ini bertujuan untuk membahas tentang pengaruh stressor lingkungan pada tahap pembenihan ikan nilem, khususnya untuk parameter suhu dan salinitas.

\section{BAHAN DAN METODE}

Data pada tulisan ini diperoleh dari data primer dan sekunder. Data sekunder dikoleksi dari hasil penelitian sebelumnya di Balai Penelitian dan Pengembangan Perikanan Budidaya Air Tawar, Bogor yang berkaitan dengan pengaruh stressor suhu dan salinitas terhadap perkembangan telur ikan nilem. Sedangkan data primer dikoleksi untuk melengkapi informasi mengenai pengaruh suhu terhadap perkembangan telur ikan nilem (tiga perlakuan suhu: 27, 29, dan $31^{\circ} \mathrm{C}$; tiga ulangan). Telur yang telah dibuahi diperoleh melalui pemijahan buatan dari stok induk ikan nilem di IP3NPAT, Cijeruk (Bobot induk betina: $185 \pm 12.91 \mathrm{~g}$; Bobot induk jantan: $104 \pm 10.82 \mathrm{~g}$ ). Telur ditetaskan di akuarium berukuran $50 \times 30 \times 30 \mathrm{~cm}$ dengan volume air $80 \mathrm{~L}$ untuk tiap perlakuan. Tiap akuarium dilengkapi dengan aerator. Perkembangan telur, derajat penetasan, mortalitas, dan sintasan diamati saat pengamatan ini.

\section{HASIL DAN BAHASAN}

Hasil dari percobaan stressor suhu menunjukkan adanya kecenderungan bahwa semakin tinggi suhu air maka semakin cepat perkembangan embrio ikan nilem. Pada suhu 25, 27, 29, dan 
$31^{\circ} \mathrm{C}$ fase pembelahan 1 sel (cleavage) berlangsung pada jam ke-1 lewat 10 menit setelah pembuahan. Sedangkan saat pembelahan kelima (32 sel), perlakuan suhu $31^{\circ} \mathrm{C}$ berlangsung saat 3 jam setelah pembuahan, lebih cepat dibandingkan perlakuan lainnya dengan waktu paling lambat ada pada perlakuan suhu $25^{\circ} \mathrm{C}$ (4 jam 24 menit). Hal tersebut juga terjadi seterusnya pada stadium blastula, gastrula, sampai ke organogenesis (Olivia et al., 2014).

Namun pada suhu $31^{\circ} \mathrm{C}$ perkembangan organnya menjadi kurang sempurna dan beberapa embrio dan larva menjadi abnormal meskipun proses penetasan berlangsung paling cepat di antara perlakuan suhu lainnya $(25,27$, dan $\left.29^{\circ} \mathrm{C}\right)($ Gambar 1).

Dari hasil pengamatan tersebut, suhu merupakan salah satu faktor eksternal atau stressor lingkungan yang sangat berpengaruh terhadap perkembangan embrio ikan nilem yang berhasil dibuahi. Pada penelitian ini, paparan suhu di luar kisaran optimal pada memiliki hubungan negative terhadap durasi masa inkubasi. Berkaitan dengan hal tersebut, hasil penelitian yang telah dipelajari pada ikan brown trout (Salmo trutta L.) juga menyatakan bahwa terdapat hubungan yang negatif antara waktu perkembangan embrio dengan peningkatan suhu di luar kisaran optimal ikan tersebut. Tren tersebut juga ditemukan pada beberapa hasil penelitian di beberapa negara yang berbeda (Realis-Doyelle, 2016).

Selain berpengaruh terhadap durasi masa inkubasi, pada penelitian ini juga diketahui bahwa suhu yang tinggi di luar batas toleransi juga menyebabkan peningkatan persentase jumlah larva ikan nilem yang cacat (abnormal). Hasil yang serupa juga menyatakan adanya peningkatan abnormalitas larva beberapa jenis ikan selama inkubasi pada suhu tinggi di luar kisaran toleransi (Lahnsteiner, 2012; Blaxter, 1992; Linares - Casenave et al., 2013; Sfakianakis et al, 2006).

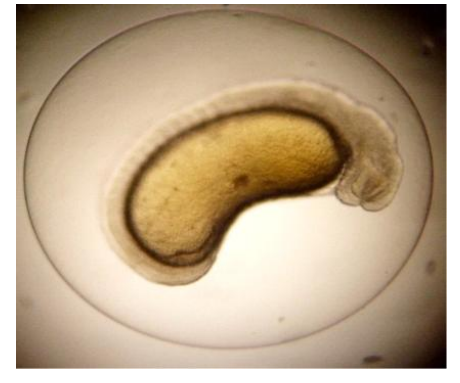

(a)

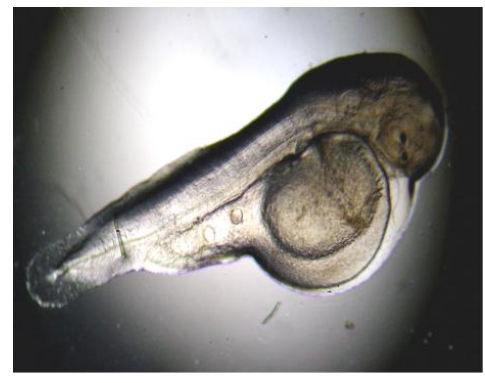

(b)

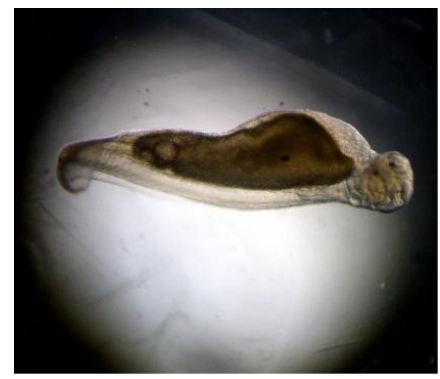

(c)

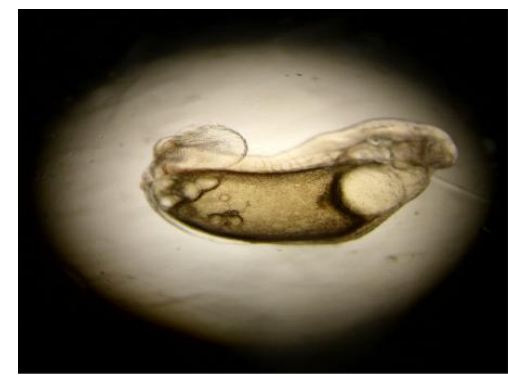

(d)

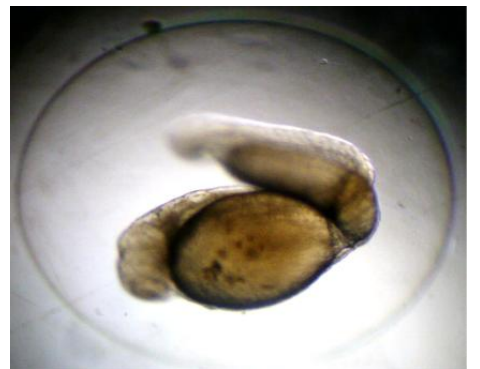

(e)

Gambar 1. Pengaruh stressor suhu pada perkembangan embrio ikan nilem (Osteochilus hasselti). (Keterangan: a. Stadium organogenesis normal; b. Embrio abnormal; c. Embrio mati; d. Larva abnormal; e. Larva mati) 


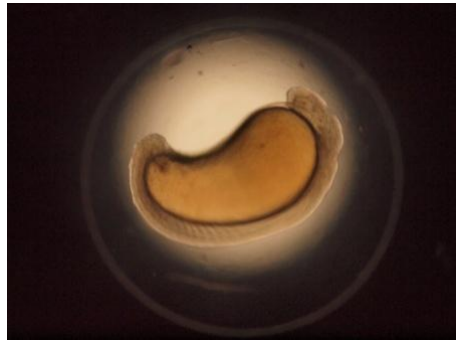

(a)

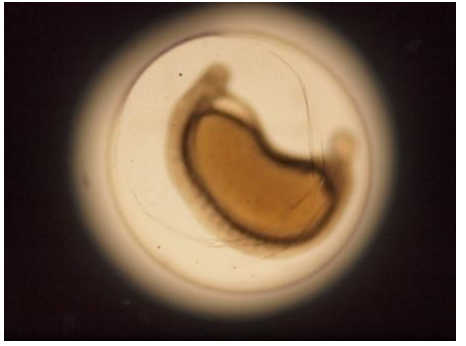

(b)

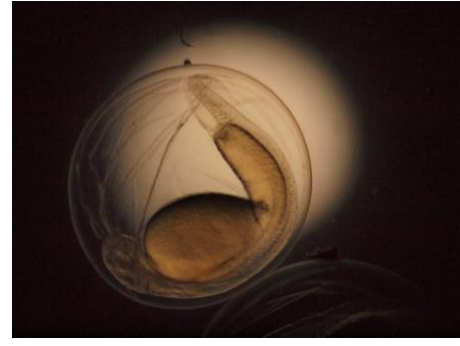

(c)

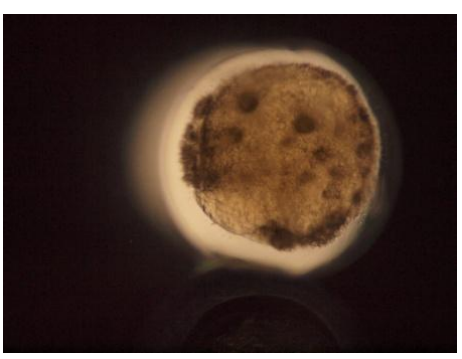

(d)

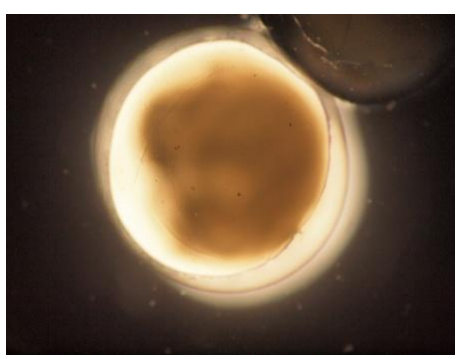

(e)

Gambar 2. Pengaruh stressor salinitas pada perkembangan embrio ikan nilem (Osteochilus hasselti). (Keterangan: a. Stadium organogenesis normal pada 0 ppt; b. Stadium organogenesis normal pada 5 ppt; c. Embrio yang tumbuh normal; d. dan e. Telur yang gagal menetas pada 10 ppt). Sumber: Prakoso \& Radona (2014)

Pengaruh lain yang dapat ditimbulkan dengan paparan suhu tinggi yaitu ukuran larva ikan yang menetas menurun secara signifikan seiring dengan kenaikan suhu inkubasi yang lebih tinggi di luar batas toleransi (Ojanguren \& Brana, 2003; Jordaan et al., 2006; Kamler et al., 1994; Schiemer et al., 2003; Kaminski et al., 2006).

Sementara itu, hasil dari percobaan stressor salinitas menunjuk-kan semakin tinggi salinitas dapat berpotensi mengganggu perkembangan embrio ikan nilem dan dapat mengakibatkan kemati-an. Pada salinitas 0, 5, dan $10 \mathrm{ppt}$ fase pembelahan 1 sel (cleavage) dan pembelahan kelima (32 sel), proses perkembangan embrio masih berlangsung normal. Namun pada tahap selanjutnya, perkembangan embrio pada perlakuan salinitas 10 ppt mulai terganggu. Sedangkan pada perlakuan 0 dan 5 ppt perkembangan embrio ber-langsung normal (Prakoso \& Radona, 2015). Pada akhirnya, perkembangan embrio pada perlakuan 10 ppt terhenti karena semua embrio mengalami kematian (Gambar 2).
Perkembangan embrio pada salinitas yang berbeda sangat dipenga-ruhi oleh kisaran salinitas media pe-meliharaan. Pada perlakuan $10 \mathrm{ppt}$, telur tidak dapat menetas karena embrio mengalami kematian. Menurut Oven (1960) dan Rykova (1970), embrio yang berkembang pada proses inkubasi dengan paparan salinitas di luar batas toleransi dapat menyebabkan abnormal-itas pada larva yang berhasil menetas. Hal inilah yang kemungkinan juga terjadi pada larva ikan nilem pada perlakuan stressor salinitas. Embrio pada ikan nilem dapat mentoleransi salinitas $5 \mathrm{ppt}$, tetapi untuk kisaran di atas 5 ppt atau sampai $10 \mathrm{ppt}$ dapat berpengaruh pada perkembangan embrio atau bahkan menyebabkan kematian. Beberapa pene-litian terdahulu juga melaporkan hal yang sama tentang pengaruh stressor salinitas terhadap perkembangan embrio pada beberapa spesies ikan, seperti ikan zebra Brachydanio rerio (Sawant et al., 2001; Haque et al., 2014), Peipsi whitefish Coregonus lavaretus (Albert et al., 2004), sichel Pelecus cultratus (Kujawa et al., 
2016), dan river herring Alosa pseudoharengus (DiMaggio et al., 2016).

Aktivitas embrio dan pembentu-kan chorionase dipengaruhi oleh faktor eksternal seperti suhu, oksigen, $\mathrm{pH}$, salinitas, dan intensitas cahaya. Pada penelitian ini, pengaruh stressor suhu dan salinitas pada derajat penetasan telur ikan nilem ditunjukkan pada tabel 1 . Derajat penetasan paling rendah pada perlakuan stressor suhu terdapat pada suhu $31^{\circ} \mathrm{C}$ $(67,74 \pm 8,44 \%)$. Sedangkan derajat penetasan paling rendah akibat stressor salinitas ada pada perlakuan 6 ppt (15.79 $\pm 11.49 \%$ ).

Tabel 1 memperlihatkan bahwa suhu mempengaruhi tingkat penetasan telur ikan nilem yang mengalami peningkatan dari suhu $25^{\circ} \mathrm{C}$ ke $29^{\circ} \mathrm{C}$ dan akhirnya mengalami penurunan pada suhu $31^{\circ} \mathrm{C}$. Telur dan larva ikan sangat sensitif terhadap fluktuasi suhu air dan cenderung memiliki toleransi yang rendah terhadap suhu jika dibandingkan dengan tahap dewasa (Das et al., 2006). Penelitian mengenai pengaruh negatif dan positif suhu rendah dan tinggi pada perkembangan embrio ini telah banyak dilakukan pada beberapa spesies (Pepin, 1991; Hart \& Purser, 1995; Hamel et al., 1997). Kenaikan suhu mengakibatkan denaturasi dan terganggunya aktivitas enzim, sehingga konsentrasi dan kecepatan enzim berkurang.

Embrio ikan nilem yang menetas pada paparan salinitas yang lebih tinggi memiliki persentase yang lebih rendah dibandingkan 0 ppt. Telur ikan yang rendah toleransinya terhadap perubahan salinitas akan memiliki persentase derajat penetasan yang semakin rendah jika terpapar pada media salinitas di luar kisaran batas toleransinya. Hal tersebut telah banyak diteliti pada beberapa spesies ikan (Haddy \& Pankhurst, 2000; Sawant et al., 2001). Potts \& Eddy (1973) juga mengungkapkan bahwa hal tersebut merupakan akibat dari konsentrasi osmotik tinggi yang berdampak pada terganggunya inti sel embrio, sehingga keseimbangan osmotik di dalam telur menjadi hilang karena tekanan osmotiknya berada di luar kapasitas osmoregulatori dari embrio yang sedang berkembang.

Tabel 1. Derajat penetasan telur ikan nilem (Osteochilus hasselti) dengan perlakuan stressor suhu dan salinitas

\begin{tabular}{lcl}
\hline \multirow{2}{*}{ Perlakuan / Treatments } & $\begin{array}{c}\text { Derajat penetasan (\%)/ } \\
\text { Hatching rate }(\%)\end{array}$ & $\begin{array}{l}\text { Referensi / } \\
\text { References }\end{array}$ \\
\hline
\end{tabular}

Suhu / Temperature

$\begin{array}{lll}25^{\circ} \mathrm{C} & 77,03 \pm 6,49 & \text { (Olivia et al., 2014) } \\ 27{ }^{\circ} \mathrm{C} & 86,15 \pm 1,72 & \text { (Olivia et al., 2014) } \\ 29^{\circ} \mathrm{C} & 89,20 \pm 5,40 & \text { (Olivia et al., 2014) } \\ 31^{\circ} \mathrm{C} & 67,74 \pm 8,44 & \text { (Olivia et al., 2014) }\end{array}$

Salinitas / Salinity

$\begin{array}{lcl}0 \mathrm{ppt} & 85.06 \pm 4.56^{\mathrm{c}} & \text { (Prakoso \& Radona, 2015) } \\ 2 \mathrm{ppt} & 81.08 \pm 5.82^{\mathrm{bc}} & \text { (Prakoso \& Radona, 2015) } \\ 4 \mathrm{ppt} & 76.60 \pm 1.91^{\mathrm{b}} & \text { (Prakoso \& Radona, 2015) } \\ 6 \mathrm{ppt} & 15.79 \pm 11.49^{\mathrm{a}} & \text { (Prakoso \& Radona, 2015) }\end{array}$


Tabel 2. Sintasan telur ikan nilem dengan perlakuan stressor suhu dan salinitas

\begin{tabular}{lcl}
\hline \multirow{2}{*}{ Perlakuan / Treatments } & Sintasan (\%)/ & Referensi / \\
& Survival rate $(\%)$ & References \\
\hline
\end{tabular}

Suhu / Temperature

$\begin{array}{lll}25{ }^{\circ} \mathrm{C} & 74,39 \pm 17,87 & \text { (Olivia et al., 2014) } \\ 27{ }^{\circ} \mathrm{C} & 87,83 \pm 12,99 & \text { (Olivia et al., 2014) } \\ 29^{\circ} \mathrm{C} & 92,86 \pm 7,03 & \text { (Olivia et al., 2014) } \\ 31^{\circ} \mathrm{C} & 84,44 \pm 7,86 & \text { (Olivia et al., 2014) }\end{array}$

Salinitas / Salinity

$\begin{array}{lll}0 \mathrm{ppt} & 97,59 \pm 1,19 & \text { (Prakoso \& Radona, 2015) } \\ 2 \mathrm{ppt} & 97,87 \pm 2,01 & \text { (Prakoso \& Radona, 2015) } \\ 4 \mathrm{ppt} & 97,59 \pm 0,86 & \text { (Prakoso \& Radona, 2015) } \\ 6 \mathrm{ppt} & 61,84 \pm 10,50 & \text { (Prakoso \& Radona, 2015) }\end{array}$

Tingkat kelangsungan hidup atau sintasan dari perlakuan suhu dan salinitas pada larva ikan nilem ditampilkan pada tabel 2. Sintasan larva paling rendah pada perlakuan stressor suhu ada pada perlakuan $25^{\circ} \mathrm{C}(74,39 \pm$ $17,87 \%)$ dan kemudian diikuti dengan perlakuan $31^{\circ} \mathrm{C} \quad(84,44 \pm 7,86 \%)$. Sementara itu, sintasan larva paling rendah pada perlakuan stressor salinitas ada pada perlakuan 6 ppt $(61.84 \pm$ $10,50 \%)$.

Suhu pemeliharaan $31^{\circ} \mathrm{C}$ dapat dikatakan hampir mendekati tingkat letal karena nilai sintasannya mengalami penurunan dibandingkan perlakuan suhu yang lebih rendah. Suhu yang terlalu tinggi pada media budidaya dapat mengakibatkan kerusakan sistem saraf pada lapisan epidermis kulit dan bagian organ sensori yang menghambat pembentukan jaringan dan terhentinya penyempurnaan organ tubuh. Akibatnya larva tumbuh abnormal dan mengalami kesulitan untuk bertahan hidup. Suhu memiliki dampak yang signifikan terhadap keberhasilan penetasan dan waktu untuk kematian 50\%, dengan guncangan panas besar menyebabkan kematian dipercepat (Landsman et al., 2011).

Suhu tampaknya memiliki pengaruh dominan pada telur dari ikan selama inkubasi (Fonds et al., 1974; Laurence \& Howell, 1981; Meeuwig et al., 2005). Tingkat kelangsungan hidup benih yang dibentuk secara signifikan berbeda antara suhu. Pada penetasan, total panjang benih secara signifikan berkurang ketika suhu meningkat.

Pada salinitas 6 ppt ini sintasan larva ikan nilem sudah mulai menurun. Paparan salinitas di luar batas toleransi dapat menyebabkan kerusakan pada bagian organ sensori yang dapat menghambat pembentukan jaringan dan terhentinya penyempurnaan organ tubuh pada larva ikan nilem. Hasil penelitian ini juga sesuai dengan pernyataan Limburg \& Ross (1995) yang menyatakan bahwa larva yang terpapar salinitas di luar batas toleransinya akan mengalami kesulitan untuk bertahan hidup karena perbedaan tekanan osmotik 
antara larva dan lingkungannya. Hal ini juga berhubungan dengan sel klorid pada telur ikan tersebut, seperti yang diungkapkan oleh Kaneko et al., (2002) bahwa sel klorid pada telur ikan merupakan osmoregulator yang berperan dalam mentoleransi paparan salinitas pada telur ikan. Kandungan sel klorid yang terpapar salinitas yang lebih tinggi akan merespon kondisi tersebut.

Menurut Bonisławska et al. (2014), gangguan akibat perubahan salinitas dapat menyebabkan perbedaan durasi embriogenesis, menurunkan derajat penetasan, meningkatkan kemungkinan abnormalitas larva, serta mengurangi persentase kelangsungan hidup larva.

\section{KESIMPULAN}

Berdasarkan data penelitian, dapat disimpulkan bahwa stressor lingkungan berupa suhu dan salinitas di luar batas toleransi dapat mengganggu perkembangan embrio ikan nilem. Stressor suhu pada embrio ikan nilem yaitu $31^{\circ} \mathrm{C}$ atau lebih, sedangkan stressor salinitas bagi embrio ikan nilem yaitu di atas 5 ppt. Hasil dari studi ini dapat dijadikan sebagai acuan dalam kegiatan budidaya ikan nilem untuk mengoptimalkan produksi benih.

\section{UCAPAN TERIMA KASIH}

Penulis berterimakasih kepada Soulina Olivia, Gleni Hasan Huwoyon, dan Deni Radona yang telah membantu dalam pengambilan data dan dokumentasi penelitian ini.

\section{DAFTAR PUSTAKA}

Albert, A., Vetemaa M., Saat T. 2004. Effects of salinity on the development of Peipsi whitefish Coregonus lavaretus marae-noides Poljakow embryos.

Annales Zoologici Fennici 41: 85-88.

Amrullah, R., Rosmawati, Mulyana. 2015. Gula darah dan mortalitas benih ikan nilem (Osteochilus hasselti) yang di pelihara pada media salinitas berbeda. Jurnal Mina Sains 1(2): 49-57.

Ayala, M.D., Martínez J.M., HernandezUrcera J., Cal R. 2016. Effect of the early temperature on the growth of larvae and postlarvae turbot, Scophthalmus maximus L.: muscle structural and ultrastructural study. Fish Physiology and Biochemistry 42: 1027.

Barton, B.A. \& Iwama G.K. 1991. Physiological changes in fish from stress in aquaculture with emphasis on the response and effects of corticosteroids. Annual Review of Fish Diseases 1: 3-26.

Berlinsky, D.L., Taylor J.C., Howell R.A., Bradley T.M., Smith T.I.J. 2004. The Effects of Temperature and Salinity on Early Life Stages of Black Sea Bass Centropristis striata. Journal of The World Aquaculture Society 35(3): 335-344.

Blaxter, J.H.S. 1992. The effect of temperature on larval fishes. Netherlands Journal of Zoology 42: 336-357. 
Bonisławska, M. 2009. Effects of salinity on the duration and course of embryogenesis in sea trout (Salmo trutta L.). Electronic Journal of Polish Agricultural Universities 12(4): 7.

Bonisławska, M., Tanski A., Szulc J., Machula S., Formicki K.. 2014. Water salinity effects on embryogenesis of the lesser sandeel, Ammodytes tobianus (Linnaeus, 1758). Central European Journal of Biology 9 (11): 1068-1077.

Das, T., Pal A.K., Chakraborty S.K., Manush S.M., Dalvi R.S., Sarma K., Mukherjee S.C. 2006. Thermal dependence of embryonic development and hatching rate in Labeo rohita (Hamilton,

1822).

Aquaculture 255, 536-541.

Dhaneesh, K.V., Devi, K.N., Kumar T.T.A., Balasubramanian T., Tissera K. 2012. Breeding, embryonic development and salinity tolerance of Skunk clownfish Amphiprion akallopisos. Journal of King Saud University - Science 24: 201-209.

Diana, A.N., Masithah, E.D., Mukti, A.T. \& Triastuti J. 2011. Embriogenesis dan daya tetas telur ikan nila (Oreochromis niloticus) pada salinitas. berbeda. Surabaya. Universitas Airlangga. 55p.

DiMaggio M.A., Breton T.S., Kenter L.W., Diessner C.G., Burgess A.I., Berlinsky D.L. 2016. The effects of elevated salinity on river herring embryo and larval survival. Environmental Bio-logy of Fishes 99: 451461.
Fonds, M., Rosenthal H., Alderdice D.F. 1974. Influence of Temperature and Salinity on Embryonic Development, Larval Growth and Number of Vertebrae of the Garfish, Belone belone. In "The Early Life History of Fish", J.H.S. Blaxter (ed.). 509-525pp.

Haddy, J.A. \& Pankhurst N.W. 2000. The effects of salinity on reproductive development, plasma steroid levels, fertilisation and egg survival in black bream Acanthopagrus butcheri. Aqua-culture 188: 115-131.

Hallare, A.V., Schirling M., Luckenbach T., Kohler H.R., Triebskorn R. 2005. Combined effects of temperature and $\mathrm{Cd}$ on developmental parameters and biomarker responses in zebrafish (Danio rerio) embryos. Journal of Ther-mal Biology 30: 7-17.

Hamel, P., Magnan, P., East, P., Lapointe, M., Laurendeau, P. 1997. Comparison of different models to predict the in situ embryonic developmental rate of fish: with special reference to white sucker (Catostomus commersoni). Canadian Journal of Fisheries and Aquatic Sciences 54: 190-197.

Hart, P.R. \& Purser, G. 1995. Effects of salinity and temperature on eggs and yolk sac larvae of the greenback flounder (Rhombosolea tapirina Günther, 1862). Aquaculture 136: 221-230.

Haque, F., Farhana T., Amin F.B., Islam M.S. 2014. Effect of different salinity exposures on the embryonic development of zebrafish (Danio rerio). Proceedings of 5th 
International Conference on Environmental Aspects of Bangladesh (ICEAB 2014). Bangladesh: 114-115.

Heming, T.A. \& R.K. Buddington. 1988. Yolk absorption in embrionic and larvae fishes. In: Hoar W.S. \& D.J. Randall (eds.), 1988. Fish physiology vol. XI. Academic Press, New York. 408-446.

Iwama, G.K., Thomas P.T., Forsyth R.B., Vijayan M.M. 1998. Heat shock protein expression in fish. Reviews in Fish Biology and Fisheries 8: 3556.

Jordaan, A, Hayhurst S.E., Kling J.L. 2006. The influence of temperature on the stage at hatch of laboratory reared Gadus morhua and implications for comparisons of length and morphology. Journal of Fish Biology 68: 724.

Kaminski, R., Kamler E., KorwinKossakowski M., Myszkowski L., Wolnicki J. 2006. Effects of different incubation temperatures on the yolkfeeding stage of Eupallasella percnurus (Pallas). Journal of Fish Biology 68: 1077-1090.

Kamler, E., Szlamínska M., Kuczynski M., Hamácková J., Kouril J., Dabrowski R. 1994. Temperature-induced changes of early development and yolk utilization in the African catfish Clarias gariepinus. Journal of Fish Biology 44: 311-326.

Kujawa, R, Lach M., Pol P., Ptaszkowski M., Mamcarz A., Nowosad J., Furgała-
Selezniow G., Kucharczyk D. 2016. Influence of water salinity on the survival of embryos and growth of the sichel larvae Pelecus cultratus (L.) under controlled conditions. Aquaculture Research 2016: 1-13.

Kaneko, T., Shiraishi K., Katoh F., Hasegawa S., Hiroi J. 2002. Chloride cells during early life stages of fish and their functional differentiation. Fisheries Science 68: 1-9.

Lahnsteiner, F. 2012. Thermotolerance of brown trout, Salmo trutta, gametes and embryos to increased water temperatures. Journal of Applied Ichthyology 28: 745-751.

Landsman S.J., Gingerich A.J., Philipp D.P., Suski C.D. 2011. The effects of temperature change on the hatching success and larval survival of largemouth bass Micropterus salmoides and smallmouth bass Micropterus dolomieu. Journal of Fish Biology 78: $1200-1212$.

Laurence, G.C. \& Howell W.H. 1981. Embryology and Influence of Temperature and Salinity on Early Development and Survival of Yellowtail Flounder Limanda ferruginea. Marine Ecology - Progress Series, 6: 11-18.

Limburg, K.E, \& Ross R.M.. 1995. Growth and mortality rates of larval american shad, Alosa sapidissima, at different salinities. Estuaries (2): 335340. 
Linares-Casenave, J., Werner I., Van Eenennaam J.P., Doroshov S. 2013. Temperature stress induces notochord abnormalities and heat shock proteins expression in fry green sturgeon (Acipenser medirostris Ayres 1854). Journal

of Applied Ichthyology, 29 : 958-967.

Meeuwig M.H., Bayer J.M., Seelye J.G. 2005. Effects of temperature on survival and development of early life stage Pacific and Western Brook Lampreys. Transactions of the American Fisheries Society, 134:19-27.

Navarro, T., Carrapato C., Ribeiro F. 2014. Effects of temperature, salinity and feeding frequency on growth and mortality of twaite shad (Alosa fallax) larvae. Knowledge and Management of Aquatic Ecosystems, 412: 07.

Ojanguren A.F. \& Brana F. 2003. Thermal dependence of embryonic growth and development in brown trout. Journal of Fish Biology, 62: 580-590.

Pepin, P. 1991. Effect of temperature and size on development, mortality, and survival rates of the pelagic early life history stages of marine fish. Canadian Journal of Fisheries and Aquatic Sciences 48: 503-518.

Petereit, C., Haslob H., Kraus G., Clemmesen C. 2008. The influence of temperature on the development of Baltic Sea sprat (Sprattus sprattus) eggs and yolk sac larvae. Marine Biology 154: 295-306.
Potts, W.T.W. \& Eddy F.B. 1973. The permeability to water of the eggs of certain marine teleosts. Journal of Comparative Physiology 82: 305-315.

Realis-Doyelle, E., Pasquet A., De Charleroy D., Fontaine P., Teletchea F. 2016. Strong Effects of Temperature on the Early Life Stages of a Cold Stenothermal Fish Species, Brown Trout (Salmo trutta L.). PLoS ONE 11(5).

Reid, S. G., Bernier N. J., Perry S.F. 1998. The adrenergic stress response in fish: control of catecholamine storage and release. Comparative Biochemistry and Physiology, Part C 120:1-27.

Sawant, M.S., Zhang S., Li L. 2001. Effect of salinity on development of zebrafish, Brachydanio rerio. Current Science 81: 1347-1350.

Schiemer, F., Keckeis H., Kamler E. 2003. The early life history stages of riverine fish: ecophysiological and environmental bottlenecks. Comparative Biochemistry and Physiology Part A 133 439-449.

Selye, H. 1974. Stress without distress. McClelland Stewart, Toronto: 171.

Sfakianakis, D.G., Georgakopoulou E., Papadakis I.E., Divanach P., Kentouri M., Koumoundouros G. 2006.Environmental determinants of haemal lordosis in European sea bass, Dicentrarchus labrax (Linnaeus, 1758). Aquaculture 254: 54-64. 
Soeseno, S. 1985. Pemeliharaan ikan di kolam pekarangan. Kanisius. Yogyakarta. 80.

Subagja J., Gustiano R., Winarlin L. 2006. Pelestarian ikan nilem (Osteochilus hasselti C.V) melalui teknologi pembenihannya. Lokakarya Nasional Pengelolaan dan Perlindungan Sumber Daya Genetik di Indonesia: Manfaat Ekonomi untuk Mewujudkan Ketahanan Nasional: 279-286. 